\title{
A Novel Collaboratively Designed Robot to Assist Carers
}

\author{
Lakshitha Dantanarayana, Ravindra Ranasinghe, Antony Tran, Dikai Liu, and \\ Gamini Dissanayake \\ Centre for Autonomous Systems, University of Technology, Sydney \\ 15, Boradway, Ultimo NSW 2007, Australia \\ \{Lakshitha. Dantanarayana, Ravindra. Ranasinghe, Antony. Tran, Dikai.Liu, \\ Gamini.Dissanayake\}@uts.edu. au \\ http://www.cas.uts.edu.au
}

\begin{abstract}
This paper presents a co-design process and an assisted navigation strategy that enables a novel assistive robot, Smart Hoist, to aid carers transferring non-ambulatory residents. Smart Hoist was codesigned with residents and carers at IRT Woonona residential care facility to ensure that the device can coexist in the facility, while providing assistance to carers with the primary aim of reducing lower back injuries, and improving the safety of carers and patients during transfers.

The Smart Hoist is equipped with simple interfaces to capture user intention in order to provide assisted manoeuvring. Using the RGB-D sensor attached to the device, we propose a method of generating a repulsive force that can be combined with the motion controller's output to allow for intuitive manoeuvring of the Smart Hoist, while negotiating with the environment.

Extensive user trials were conducted on the premises of IRT Woonona residential care facility and feedback from end users confirm its intended purpose of intuitive behaviour, improved performance and ease of use.
\end{abstract}

Keywords: Assistive Robots, Aged Residential Care, Patient Hoist, Human Robot Interaction, Navigation Assistance

\section{Introduction}

Assistive robots [1-4] are devices that work collaboratively with a range of human users; as assistants, tools and as companions. These machines are expected to be able to perceive the user's behaviour and needs, communicate in a human-centred manner, and respond safely and efficiently to directions. Although machines for assisting users in performing difficult tasks have already been adopted in many industry sectors, the potential of assistive robotics in aged care has only gained attention in the last few decades.

Many assistive robots have emerged in recent years such as smart wheelchairs [5], smart walkers [6], and telepresence robots [7]. These devices assist people in their daily living activities whether they are disabled or senior citizens, enhancing their quality of life. 
Due to the increasing demand for aged care services and the continuing decline in the relative availability of informal carers, the scarce trained aged care workforce often find themselves overworked to meet community expectations. This combined with the high rate of work-related musculoskeletal injuries amongst carers [8-11] and injuries to non-ambulatory residents occurring during transfer (eg. bed to chair, chair to toilet and bath), gives rise to significant costs and health \& safety risks. Therefore it is equally important to assist these stretched carers in order to improve safety and the quality of care services.

Motivated by this real need, the research work presented in this paper is based on the Smart Hoist, a modified conventional patient lifter(standard hoist) with the primary aim of reducing lower back injuries in carers, and improving the safety of carers and patients during transfer in aged care facilities. The main focus of this paper is to present the collaborative design methodology used in developing a novel motorised patient lifting device and the human robot interaction approaches used in controlling it. The paper also highlights the navigation assistance methodologies incorporated in the Smart Hoist to further improve the carer's experience.

Obstacle detection and avoidance has always been an integral part any mobile robot system [12-14]. This becomes more relevant in cluttered and confined spaces. The main hurdle in implementing obstacle avoidance is the disparity in the user intention and the robot's movement. Either the user's commands override the system, or the robot takes control of the vehicle.

\section{Collaborative Design Process of the Smart Hoist}

The Smart Hoist device is targeted at a group of professionals specialised in aged care, performing the specific tasks of resident lifting and transferring. Therefore the active participation of the carers was crucial even during the early stages of the design process. The ultimate goal was to build a device the carers would be comfortable working with. This was one of the key pillars of the overall approach in the design of the Smart Hoist.

The co-design approach enabled the involvement of future users who are familiar with the routine activities in an aged care facility in the design process, which empowered the carers to make high level design decisions. The study was conducted at the IRT Woonona aged care facility. Selection of the project participants was done during the preliminary meetings with the help of IRT management. A group of keen participants were chosen from the carers to participate in subsequent co-design workshops.

The process of designing, developing and commissioning a single Smart Hoist was performed over a period of 18 months commencing in December, 2012. At the beginning of the co-design process, several knowledge-building meetings were conducted to gain insight into resident lifting and transporting. During these meetings a productive working relationship between the project participants and the members of the research team was also formed. 
Subsequent co-design workshops involving 4-5 carers and one UTS member who specialised in co-design were conducted as model building exercises [15]. Insight acquired during the knowledge-building meetings was quite resourceful in forming the mockup models during these workshops.

The objectives of these co-design workshops were to design the Smart Hoist's user interface, external housing structure, key functionalities of the device and the batteries. Key design considerations that were focused on during the codesign workshops include driving confidence, comfort \& ease of use, and safety $\&$ efficiency. Some key outcomes from the discussions were:

- Assisted manoeuvring especially when loaded with a patient

- Weight measurement and Body Mass Index(BMI) calculation of the patient

- Ability to monitor the environment (esp. under furniture, beds)

- Rear view mirror to monitor the environment behind the carer

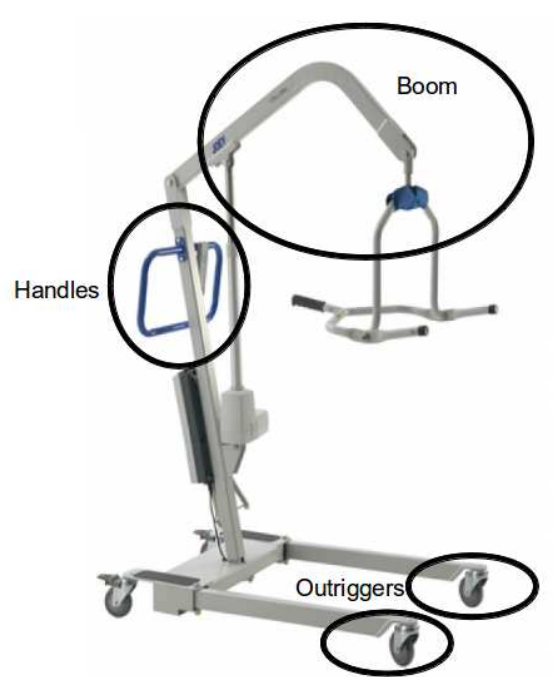

(a)

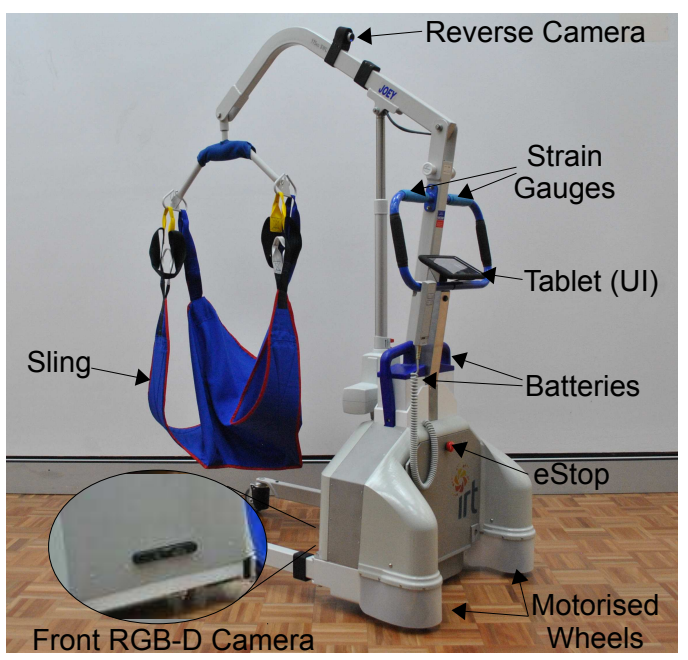

(b)

Fig. 1: (a) Standard Joey ${ }^{\top M}$ Lifter from AIS healthcare Pty. Ltd. (b) UTS-IRT Smart Hoist

The UTS-IRT Smart Hoist incorporates and builds upon the standard Joey ${ }^{T M}$ Lifter from AIS healthcare Pty. Ltd. As part of the transformation the Joey ${ }^{T M}$ Lifter has undergone a series of modifications which were completed with extreme care to avoid compromising its structural integrity, comparison between the two can be seen in Fig. 1. Modifications include:

- The linear actuators controlling the boom and the outriggers have been retrofitted with encoders to determine their location 
- Strain gauges have been placed on the boom, which combined with the boom angle allow for patient weight calculations.

- Strain gauges have also been placed onto the handlebars of the Smart Hoist in order to detect the forces the carer applies to the hoist

- Rear caster wheels replaced with the Revolution $2^{T M}$ assembly from 221 Robotic Systems

- A High Definition RGB camera placed at the top of the boom which provides the carer with information about the environment behind them

- A RGB-D sensor positioned at the bottom of the hoist facing forward. The camera provides the carer with information which is usually obstructed by a hanging patient, additionally it provides vision of objects at the ground level (eg. underneath beds, furniture)

- A Google@Nexus 7 provides a user interface to display system status(battery charge, time, EStop status, etc), camera views, and weight information.

A more detailed description of the parts and components can be found in [16].

\section{User Intention Recognition}

A major design consideration was to ensure that the method of manoeuvring a standard hoist and the Smart Hoist were as similar as possible. A simple admittance control strategy [16] is used to control the Smart Hoist.

When the carer exerts the force $F$ on the handles of the hoist, a collective opposing force of $C v$ is applied when the system moves at velocity $v$. If we assume the mass of the system $m$ and the parameter $C$ are fixed, the response of the system would be identical whether or not the system is loaded. By applying the simple motion equation we get (1), giving the first order system (2), which can be discretized to (3) at instance $k$. In order to ensure that the Smart Hoist behaved similarly to a standard mechanical hoist, the research team identified the major motion patterns [16] required for the everyday use of the standard hoist. The motion logic [16] evaluates the trends in the strain gauge values and determines the Smart Hoist's motion and its linear velocities $v_{x}$ and $v_{y}$ in directions $x, y$, and its angular velocity, $\omega$ in the $z$ axis by the use of (3). Fig. 2 represents a high level block diagram of the control system.

$$
\begin{gathered}
F-C v=m \dot{v} \\
H=v / F=\frac{1 / C}{(m / C) s+1} \\
v_{k}=\frac{F_{k}+m \cdot v_{k-1}}{m+C}
\end{gathered}
$$




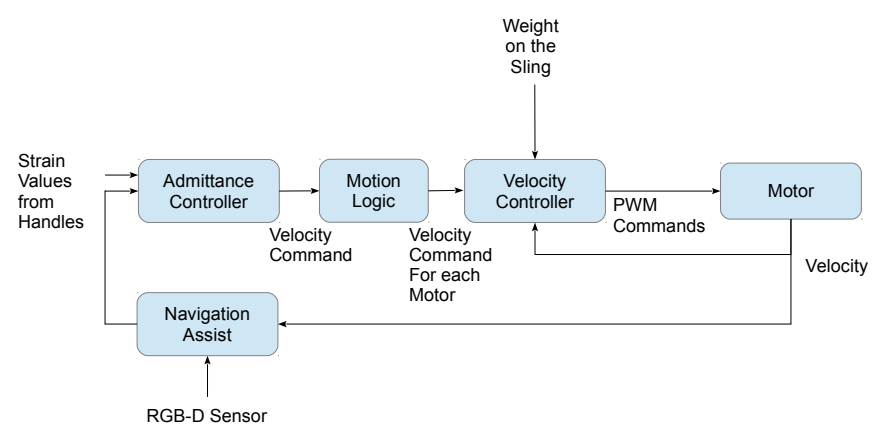

Fig. 2: Block diagram of the Controller.

\section{Navigation Assistance Based on Environmental Data}

During the co-design workshops it was mentioned by carers that, in their busy daily schedules they find it difficult to navigate through narrow passageways and door frames with a hoist, especially when loaded. Therefore the Smart Hoist is designed to provide assistance when performing tight manoeuvres to minimise the effort required by the carer to navigate through these tight spaces.

\subsection{Sensing the Environment}

The Smart Hoist makes use of the point cloud data generated from the RGB-D sensor located at its base. The Asus RXtion PRO Live is capable of publishing point-clouds at a frequency of $30 \mathrm{~Hz}$. The point clouds are first processed to filter spurious noise and a crop filter is then applied to remove the floor and hoist sling which is normally in the sensor's field of view. Since the RGB-D sensor is mounted at a fixed elevation, this process is fairly trivial. The point cloud is then segmented using a nearest neighbour method to identify and remove the outriggers. It is then projected to the ground plane to generate a $2 \mathrm{D}$ birds-eye view image.

The image is then used to extract the Unsigned Euclidean Distance Transform (DT). For a binary image with the set of occupied pixels $V$, the formed DT image in which each pixel value $(x)$ indicates the minimum distance from that point to the closest occupied $\operatorname{pixel}(v \in V)$ is given by (4).

$$
D T(x)=\min _{v \in V}|x-\mathbf{v}|
$$

This is a linear time $O(n)$ computation and requires just two passes over the image [17]. Fig. 3 represents outputs of each stage of this process.

\subsection{Navigation Assistance}

With the DT image, it is simple to obtain the distance from the edge of each outrigger to the closest obstacle. Assistance is provided when an outrigger reports a distance less than the predefined safety margin. A sideway ( $y$ direction) 


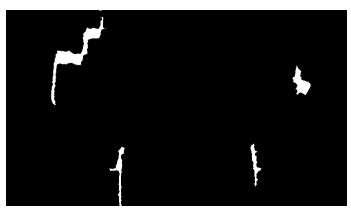

(a)

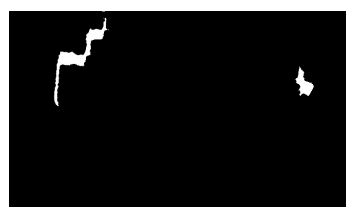

(b)

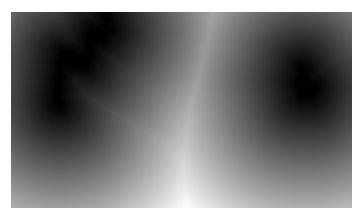

(c)

Fig. 3: (a) Ground plane projection of the point-cloud, (b) Environment Map after removal of outriggers, (c) DT image of the environment map.

repulsive force in the direction of the outrigger which is least susceptible to collision is introduced. This repulsive force is applied in par with the strain gauge inputs, and as a factor of the forward ( $x$ direction) input force. The new input force to the system in (3), $F$ is given by the empirically determined equation seen in (5). The parameter $P$ is derived from the closeness of the outrigger given by the DT value above. The constant $K$ scales the output of $P$ so that the wheel angle $\alpha$ is between $0^{\circ}-60^{\circ}$ which is an empirically determined safe operating angle for small confined regions.

$$
\begin{aligned}
F_{y} & =F_{y}, \text { handles } \\
F_{x} & =F_{x, \text { handles }} \\
\text { wheel angle, } \alpha & =\tan ^{-1}\left(\frac{F_{y}}{F_{x}}\right)
\end{aligned}
$$

\subsection{Evaluation}

To measure the level of assistance required to minimise collision when passing through the narrow doorway shown in Fig. 4, two experiments were conducted. The Smart hoist is initially placed at the start position. In the first experiment, the Smart Hoist is pushed through the doorway and in the second experiment the Smart Hoist is driven using a constant virtually simulated force input of $15 N$ to the handles. The Fig. 5 shows the actual input forces and the forces generated by the assistance strategy for the hoist's outriggers to avoid collision with obstacles.

As seen in the time-force plots, the navigation assistance algorithm automatically generates the repulsive forces in real-time that are necessary to avoid collision so that the Smart Hoist can navigate through the doorway without colliding. However, the two scenarios cannot be directly compared as it is impossible to introduce a forward only force on the handles when pushed manually. Because these forces are proportional to the carer's input force there would never be a repulsive spring action that could negatively affect the carer's experience.

\section{$5 \quad$ User Trials}

The design of the Smart Hoist was a reiterative process, which involved a series of demonstrations and user trials at IRT Woonona care facility. The user trials 


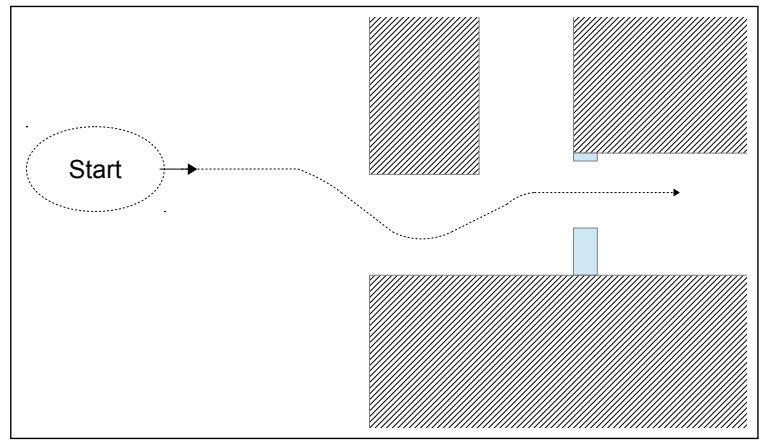

Fig. 4: The narrow doorway used for the experiments in Section 4.3.

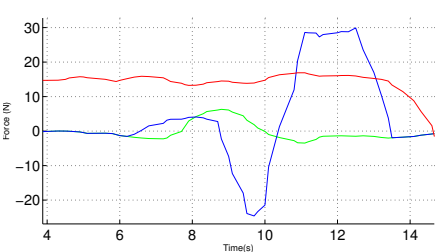

(a)

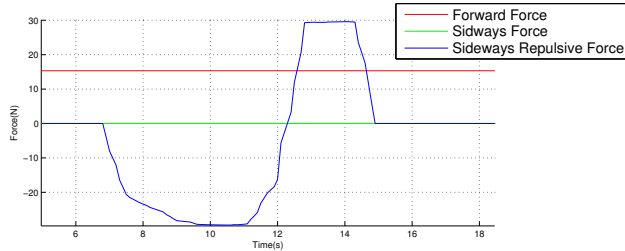

(b)

Fig. 5: Push using (a) exerting forces on the handles, (b) simulated force on the handles.

described below were conducted prior to the implementation of the navigation assistance strategy to obtain initial user feedback. (Fig. 6).

The first prototype of the Smart Hoist was constructed to meet the design specifications that were laid down during the earlier co-design workshops. A user trial with this prototype was conducted early December, 2013 in order to gauge the carer's first impressions of the Smart Hoist. 15 volunteers were introduced to the use of the Smart Hoist and were asked to perform basic manoeuvres. Feedback received from carers during the early design stages of the project and the user trial was extremely valuable in the development of the Smart Hoist. Table 1 lists a summary of important comments from that trial. The Smart Hoist underwent many hardware and software changes based on the feedback.

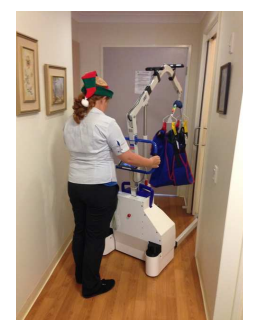

(a)

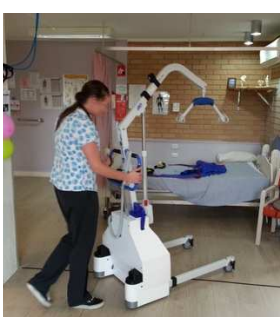

(b)

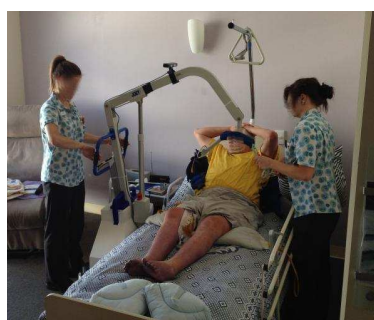

(c)

Fig. 6: User trials conducted at IRT Woonoona, Australia. 
The second trial was conducted in late March 2014 with approximately 50 carers. The carers participated in an interactive training workshop, after which they were asked to perform a complete patient transfer from bed to bathroom in a simulated environment. The exercise included complex manoeuvres such as lifting a patient from a bed, navigating through corridors and around tight corners and lowering the patient into a chair. The aim of this experiment was to assess the intuitiveness and responsiveness of the Smart Hoist in comparison to a standard hoist in a routine exercise. The preliminary outcomes of the second trial upheld the results from the first user trial.

Table 1: Summary of carers' comments from the first user trial

\begin{tabular}{|c|c|c|c|}
\hline $\begin{array}{l}\text { Evaluation } \\
\text { category }\end{array}$ & $\begin{array}{l}\text { Evaluation } \\
\text { Criteria }\end{array}$ & $\begin{array}{l}\text { Score } \\
\text { out of } \\
10\end{array}$ & Additional Comments \\
\hline Confidence & $\begin{array}{l}\text { Driving \& Turn- } \\
\text { ing }\end{array}$ & 7 & $\begin{array}{l}\text { - "Need to be slow when moving side- } \\
\text { ways and turning under load" } \\
\text { - "Too slow to change to sideways mode" }\end{array}$ \\
\hline \multirow{4}{*}{$\begin{array}{l}\text { Comfort } \\
\text { Ease of use }\end{array}$} & Handles \& Grips & 6 & - "Needs too much force" \\
\hline & Screen & 8 & $\begin{array}{l}\text { - "Bigger icons and text" } \\
\text { - "High contrast and brightness" } \\
\text { - "Include descriptions for the icons" } \\
\text { - "Arrow to indicate the wheel direction" }\end{array}$ \\
\hline & Batteries & 9 & $\begin{array}{l}\text { - "Long but OK" } \\
\text { - "No heavier please" } \\
\text { - "Must charge fast" }\end{array}$ \\
\hline & Cameras & 9 & $\begin{array}{l}\text { _ "Need a higher field of view" } \\
\text { _ "Can I rely on it? Will it give me a false } \\
\text { sense of security?" }\end{array}$ \\
\hline $\begin{array}{l}\text { Safety \& Effi- } \\
\text { ciency }\end{array}$ & Overall & 10 & - "I was never worried about my feet" \\
\hline
\end{tabular}

\section{Conclusion}

This paper describes a navigation strategy for a novel assistive robot developed by the University of Technology, Sydney, working collaboratively with the staff at IRT Woonona Residential Care Facility. The aim was to reduce the likelihood of workplace injuries being sustained by care workers in aged and disabled care sectors when transferring residents.

Smart Hoist is an extension of a standard hoist, apart from being motor driven, it also offers a number of attractive features. Similar to a standard hoist, the it is operated by applying forces on its handles. This intuitive control system allows carers to seamlessly migrate to the Smart Hoist without an added learning curve that is usually associated with most assistive robotic devices. It also senses 
its environment using an RGB-D sensor in order to provide navigation assistance to the carer in confined spaces.

Further evaluation of the benefits of the Smart Hoist, using Electromyographic (EMG) readings of the major muscles involved in manoeuvring the hoist is planned to be conducted in a forthcoming extended user trial. A thorough postdeployment evaluation and comprehensive comparison with the second user trial outcomes will also be a part of this exercise. Future work also includes further extending and improving the navigation assistance algorithm.

\section{Acknowledgments}

This work was supported in part by IRT Research Foundation, Australia and the Centre for Autonomous Systems, University of Technology, Sydney (UTS), Australia.

We thank the management, the staff and the residents of IRT Woonoona care facility, Australia for their involvement in the design development, implementation and evaluation of the smart hoist.

We also acknowledge A/Prof Jaime Valls Miro and Prof. Lynn Chenoweth for their guidance and Dr. Michael Behrens, Ms. LiYang Liu, Mr. Stefan Lie and Mr. Remi Bouskila for the assistance given in developing the Smart Hoist.

\section{References}

1. Jayawardena, C., Kuo, I.H., MacDonald, B.A.: An efficient programming framework for socially assistive robots based on separation of robot behavior description from execution. In: 2013 6th IEEE Conference on Robotics, Automation and Mechatronics (RAM). pp. 150-155. IEEE (Nov 2013), http: //ieeexplore. ieee.org/xpls/abs \_all.jsp?arnumber $=6758575$ http: //ieeexplore. ieee.org/lpdocs/epic03/wrapper.htm?arnumber $=6758575$

2. Torta, E., Oberzaucher, J., Werner, F., Cuijpers, R.H., Juola, J.F.: Attitudes Towards Socially Assistive Robots in Intelligent Homes: Results From Laboratory Studies and Field Trials (Dec 2012), http://humanrobotinteraction.org/ journal/index.php/HRI/article/view/60

3. Dahl, T.r., Boulos, M.: Robots in Health and Social Care: A Complementary Technology to Home Care and Telehealthcare? Robotics 3(1), 1-21 (Dec 2013)

4. Tanaka, H., Yoshikawa, M., Oyama, E., Wakita, Y., Matsumoto, Y.: Development of Assistive Robots Using International Classification of Functioning, Disability, and Health: Concept, Applications, and Issues. Journal of Robotics 2013, 1-12 (2013), http://www.hindawi.com/journals/jr/2013/608191/

5. Hillman, M., Hagan, K., Hagan, S., Jepson, J., Orpwood, R.: The Weston wheelchair mounted assistive robot - the design story. Robotica 20(02), 125-132 (Apr 2002), http://journals.cambridge.org/abstract \ _S0263574701003897http://www . journals . cambridge.org/abstract \ _S0263574701003897

6. Rentschler, A.J., Cooper, R.A., Blasch, B., Boninger, M.L.: Intelligent walkers for the elderly: performance and safety testing of VA-PAMAID robotic walker. Journal of rehabilitation research and development 40(5), 423-31 (2003), http: //www.ncbi.nlm.nih.gov/pubmed/15080227 
7. Kristoffersson, A., Coradeschi, S., Loutfi, A.: Towards evaluation of social robotic telepresence based on measures of social and spatial presence (2011), http://www . diva-portal .org/smash/record.jsf?pid=diva2: 542612

8. Dawson, A.P., McLennan, S.N., Schiller, S.D., Jull, G.A., Hodges, P.W., Stewart, S.: Interventions to prevent back pain and back injury in nurses: a systematic review. Occupational and environmental medicine 64(10), 642-50 (Oct 2007), http://www.pubmedcentral.nih.gov/articlerender.fcgi?artid= 2078392 \\&tool=pmcentrez \&rendertype=abstract

9. Fragala, G., Bailey, L.P.: Addressing occupational strains and sprains: musculoskeletal injuries in hospitals. AAOHN journal : official journal of the American Association of Occupational Health Nurses 51(6), 252-9 (Jun 2003), http: //europepmc.org/abstract/MED/12846458

10. Pellatt, G.C.: The safety and dignity of patients and nurses during patient handling. British journal of nursing (Mark Allen Publishing) 14(21), 1150-6 (2005), http://www.ncbi.nlm.nih.gov/pubmed/16475436

11. Reichert, P.: Patient Handling Ergonomics. Ph.D. thesis, New Jersey Institute of Technology (2004)

12. Levine, S.P., Bell, D.a., Jaros, L.a., Simpson, R.C., Koren, Y., Borenstein, J.: The NavChair Assistive Wheelchair Navigation System. IEEE transactions on rehabilitation engineering : a publication of the IEEE Engineering in Medicine and Biology Society 7(4), 443-451 (Dec 1999), http://www.ncbi.nlm.nih.gov/pubmed/ 10609633

13. Park, J.B., Lee, B.H., Chung, W.K.: Reflective force navigation control for a mobile robot using a state transition diagram. Proceedings 2003 IEEE/ASME International Conference on Advanced Intelligent Mechatronics (AIM 2003) 0(Aim), 52-57 (2003), http://ieeexplore.ieee.org/lpdocs/epic03/wrapper. htm? arnumber $=1225071$

14. Song, K.T., Jiang, S.Y.: Force-cooperative guidance design of an omni-directional walking assistive robot. 2011 IEEE International Conference on Mechatronics and Automation pp. 1258-1263 (Aug 2011), http://ieeexplore.ieee.org/lpdocs/ epic03/wrapper .htm?arnumber $=5985842$

15. Lie, S., Liu, D., Bongers, B.: A cooperative approach to the design of an Operator Control Unit for a semi-autonomous grit-blasting robot. In: Australasian Conference on Robotics and Automation(ACRA) (2012), http://www.araa.asn. au/acra/acra2012/papers/pap144.pdf

16. Ranasinghe, R., Dantanarayana, L., Tran, A., Lie, S., Behrens, M., Liu, L.: Smart Hoist: An Assistive Robot to Aid Carers. In: 13th International Conference on Control, Automation, Robotics and Vision(ICARCV) (2014)

17. Felzenszwalb, P., Huttenlocher, D.: Distance Transforms of Sampled Functions. Tech. rep., University of Cornell (2004), http://ecommons . library . cornell.edu/ handle/1813/5663 